Наумова Елена Вадимовна

кандидат социологических наук, доцент кафедры социологии

Новосибирского государственного университета

экономики и управления «НИНХ»

\section{СУЩНОСТЬ, СТРУКТУРА И СВОЙСТВА БАЗОВОЙ МОДЕЛИ СОЦИАЛЬНОГО ДЕЙСТВИЯ}

Аннотация:

В статье обоснован подход к определению сущности и структуры «социального действия». Предложены критерий "социальности» и метод идентификации, с помощью которого сформирована базовая модель «социального действия». Дано определение "социальности» и установлено основное свойство «социального действия».

Ключевые слова

социальное действие, критерий «социальности», сущность "социального», структура и свойства социального действия.

\section{Naumova Elena Vadimovna}

PhD in Social Science, Assistant Professor, Social Science Department, Novosibirsk State University of Economics and Management

ESSENCE, STRUCTURE AND FEATURES OF THE BASIC MODEL OF SOCIAL ACTION

The article justifies the approach to definition of the essence and structure of 'social action' concept. The author suggests a criterion of 'sociality' and the method of identification, which allowed to produce a basic model of social action. The paper presents a definition of sociality and distinguishes the basic feature of the social action.

Keywords:

social action, criterion of 'sociality', essence of 'social', structure and features of social action.

В предыдущей статье установлено, что общая для индивидов, групп и «институтов» сущность «социального» может быть найдена только с помощью «деятельностной» модели [1]. В свою очередь для выявления этой сущности нужно определить результат социального действия и исходный предмет, позволяющий достичь этого результата. Здесь возникает проблема идентификации самого фракта социального действия.

В нашей публикации «Анализ моделей социальности в современной социологии» был рассмотрен подход М. Вебера к объяснению феномена «социальности» через способность субъекта деятельности «ориентироваться на другого» [2]. Недостатки такого подхода очевидны. Ведь субъект может скрывать, на кого именно он «ориентируется» в каждый момент и почему на некоторых «других» он ориентируется иначе, чем на прочих «других». Однако главная проблема состоит в том, что «ориентация на другого» может иметь место в «биологическом» (репродуктивное поведение) и «психическом» (зависть, ревность) действии. Невозможно определить, что поведение субъекта является результатом именно социального действия, а не «психического» или «биологического».

И.Ф. Девятко в монографии, посвященной исследованию «теоретического диспута о действии», так оценивает перспективу определения сущности социального действия: «Осознание почти неразрешимых и, хуже того, несовместимых трудностей делает быстрое продвижение к разгадке маловероятным» [3, с. 273]. Мы полагаем, что данный вывод обусловлен тем, что в рассмотренных теориях авторы декларировали «социальность» выбранной ими деятельности без обоснования этого выбора.

В данной статье мы попытались найти решение проблемы определения сущности «социального» с помощью принципиально иного подхода, который называем «конструктивным». В качестве первого шага сформулируем две базовые гипотезы, которыми будем руководствоваться при решении поставленной задачи.

- Гипотеза деятельности. Социальное действие является деятельностью. У нее есть особый результат, способ (технология) его получения, субъект, средство и исходный предмет. Идентифицировать сущность «социального» можно лишь установив результат и исходный предмет этой деятельности.

- Гипотеза универсальности. Субъектами социального действия могут быть индивиды, группы индивидов и социальные институты. Сущность «социальности» не зависит от состава и структуры субъекта деятельности.

В основе авторского подхода к определению сущности «социального» лежит идея Э. Дюркгейма о том, что качество «социальности» может иметь различную степень выраженности [4]. Соответственно, это качество можно выявить, сравнивая «более социальное» и «менее социальное» действия. Для практической реализации этого подхода необходимо следующее: 
- выбрать критерий «социальности» действия и разработать на его базе метод сравнения разных социальных действий;

- подобрать для сравнения социальные действия с разной величиной критерия «социальности» и определить, какие фракторы в сопоставляемых деятельностях влияют на изменение величины критерия «социальности»;

- сформулировать на основе выявленных факторов определение социального действия и реконструировать структуру этой деятельности.

Наиболее сложной проблемой является выбор критерия «социальности» действия. Недостатки веберовской «ориентации на другого» были рассмотрены ранее. Э. Дюркгейм основными признаками «социальности» факта считал его объективный и принудительный характер [5]. Однако эти признаки также нельзя признать специфически «социальными»:

- Во-первых, биологические (голод) и психические (страх) фракторы тоже действуют объективно и принудительно.

- Во-вторых, «принудительность» и «сопротивление» являются не единственными признаками «социальности». Поощрение субъекта и содействие ему также свидетельствуют о «социальности» его действий.

- В-третьих, отсутствие «сопротивления» или «поощрения» не обязательно означает «несоциальность» действий субъекта. Причиной может быть безразличие социума к рутинным социальным действиям субъекта.

Подход Дюркгейма удобен тем, что явная реакция на действие субъекта достаточно легко идентифицируется. Сопротивление социума действиям субъекта действительно может служить индикатором наличия в этих действиях «социальности». Таким образом, критерий «социальности» действия должен, по мнению автора, удовлетворять следующим требованиям:

- легко распознаваться;

- исключать влияние биологических и психических факторов;

- быть удобным для поиска и сравнения пары «более социального» - «менее социального» действий.

Сложность представляет выполнение второго требования, поскольку необходимо исключить «биологическое» и «психическое», пропуская только «социальное». Роль такого индикатора «социальности» может выполнять «социальный институт». Существующая в социологии практика употребления термина «социальный институт» позволяет утверждать, что сущности, которые этим термином обозначаются, не имеют ни физического тела, ни индивидуальной психики. Например, налоговый инспектор при выполнении работы руководствуется наличием или отсутствием «социальных» оснований для расчета налогов субъекта, игнорируя при этом фризические (рост, вес), биологические (пол, возраст) и психические (эмоции) особенности налогоплательщика.

Такое безразличие социального института к «биологическому» и «психическому» дает возможность использовать его в качестве индикатора социального действия. Если социальный институт отреагировал на какое-то событие или чье-то действие, значит, в этом событии или действии было что-то не «биологическое» и не «психическое». Это «что-то» мы называем «социальным», осознавая при этом, что по объему и содержанию оно отличается от «общественного» (или «коллективного»), хотя иногда эти термины употребляются как синонимы.

В основе предлагаемого подхода выявления фрактора «социальности» лежат следующие идеи:

- Если социальный институт реагирует на некоторое действие индивида (группы индивидов, другого социального института), значит, в этом действии присутствует фрактор «социальности». Если реакции социального института нет, то фрактор «социальности» в действии отсутствует.

- Со временем социальный институт может кардинально изменить свое отношение к данному действию, что проявляется в изменении его реакции на это действие.

- Причиной разной реакции социального института на одно и то же действие индивида (группы индивидов, другого социального института) может быть только разная величина фактора «социальности» в этом действии. Если удастся установить эту причину, то она и будет искомым фрактором «социальности» данного действия.

Таким образом, для выявления фактора «социальности» мы используем критерий изменения реакции социального института на некоторую деятельность субъекта. Если реакция социального института менялась, то какой-то фрактор, определяющий «количество социальности» в действии, был институтом воспринят как изменившийся, и этот фрактор можно установить. На данном предположении базируется предлагаемый метод идентификации социального действия. Его суть состоит в следующем:

- выбирается социальный институт, не претерпевший существенных трансформаций в течение некоторого периода;

- выбирается действие индивида или группы индивидов, реакция на которое у данного института в течение этого периода кардинально менялась. 
Причина изменения реакции социального института и есть искомый фрактор, определяющий «социальность» данного действия для этого института. В качестве примера рассмотрим изменение отношения католической церкви к распространению гелиоцентрической идеи Н. Коперника. В 1543 г. церковь разрешила издание работы ученого «Об обращении небесных сфер», В мае 1620 г. церковная цензура полностью осудила и запретила печатать эту книгу, а в 1835 г. запрет был отменен. Таким образом, одна и та же деятельность (распространение гелиоцентрических идей с помощью книг) сначала для церкви была «несоциальным» действием, затем стала «социальным», а после снова потеряла «социальность».

Причиной этого были достижения науки. В момент появления гипотеза Коперника о движении планет вокруг Солнца опровергалась астрономическими наблюдениями. В 1609 г. Кеплер сорормулировал три закона движения планет относительно Солнца, а в 1610 г. Галилей обнаружил спутники Юпитера, разрушающие птолемеевскую систему строения Вселенной. Это, по мнению инквизиции, подрывало основы католического вероучения. К началу XIX в. влияние церкви на общество в значительной мере было утрачено и борьба с «ересью» потеряла значимость. Кроме того, все исследования подтверждали истинность гелиоцентрической системы. Отрицание очевидного стало неудобным для церкви, и в 1835 г. работы Коперника, Кеплера и Галилея были убраны из списка запрещенных книг.

Этот пример показывает, что причина изменения отношения социального института (церкви) к действию (распространению книг с гелиоцентрическими идеями) - не в действии, а в самом институте. Истинной причиной реакции является способность действия изменять условия существования социального института в рамках социальной системы. Если действие не влияет на эти условия, институт не реагирует на него. Если влияет - следует реакция. Если действие ухудшает условия деятельности социального института, принимаются меры противодействия, если улучшает - меры содействия.

Таким образом, причиной разной реакции социального института на одно и то же действие (или событие) являются представления этого института о том, как в результате данного действия изменятся условия существования самого института. Это также справедливо для индивидов и социальных групп. Поэтому в дальнейшем мы употребляем термин «социальный субъект», понимая под ним как индивида, так и группу, и социальный институт.

Для объяснения сущности и свойств социального действия необходимо определить основные понятия:

- совокупность представлений [6] социального субъекта о том, что можно [7] при возникновении некоторого события, называется фрактором свободы;

- совокупность представлений социального субъекта о том, чего нельзя при возникновении некоторого события, называется фрактором необходимости [8];

- ординарным социальным действием называется деятельность субъекта, не изменяющая его фракторов свободы и необходимости;

- неординарным социальным действием называется деятельность субъекта, изменяющая его фрактор свободы и/или фрактор необходимости;

- социальное действие - это деятельность субъекта по фрормированию своего фрактора свободы и/или фрактора необходимости.

Соответственно, несоциальным действием является любое событие, которое субъект не связывает со своими представлениями о том, что можно и чего нельзя. Например, несоциальным действием являются фрраза или надпись на незнакомом языке, смысл которой остался субъекту неизвестным и не повлиял на его факторы свободы и необходимости.

Мы считаем, что социальное действие - это деятельность, результатом которой является совокупность представлений субъекта о том, что можно, и чего нельзя при возникновении некоторого события. Из этого определения следуют два важных вывода:

1. Субъектом социального действия является тот, кто, воспринимая некоторое событие, фрормирует свои представления о том, что в возникшей ситуации можно и чего нельзя [9]. Это означает, что одно событие может порождать столько социальных действий, сколько субъектов о нем узнают. Причем в зависимости от индивидуальных фракторов свободы и необходимости для одних субъектов это событие - ординарное действие, для других - неординарное, а для кого-то - вообще не социальное.

2. «Социальность» субъекта возникает благодаря его способности формировать и изменять собственные представления о том, что можно и чего нельзя. Если субъект сохраняет эту способность, он остается «социальным» вне зависимости от того, взаимодействует он с другими субъектами или находится в изоляции от них. Утрата субъектом этой способности означает для него потерю «социальности», даже если при этом он продолжает находиться среди других субъектов.

Результатом социального действия является «представление», т. е. некоторый образ, которым пользуется субъект. Но всякий образ - это информация. Следовательно, социальное действие - это деятельность по производству информации, а значит, ее предметом также может 
быть только информация [10]. Предмет социального действия - информация о событиях, в связи с которыми у субъекта формируются представления о том, что можно и чего нельзя.

Технология (способ) социального действия - это последовательность операций (функций) преобразования предмета (информации о событии, предметном действии) в результат (факторы свободы и необходимости субъекта). Применительно к социальному действию способ включает в себя получение информации о некотором событии, анализ этой информации (сопоставление с тем, что ожидалось) и принятие решения о сохранении или изменении представлений о том, что можно и чего нельзя при наступлении такого события. Событием может быть как чье-то целенаправленное действие, так и природное явление.

В общем случае средство деятельности - это то, чем воздействуют на предмет для получения результата. Для социального действия средство - это методы получения информации о происходящих событиях, анализа (сравнения прошлых представлений с новыми фрактами) и формирования новых фракторов свободы и необходимости.

Таким образом, социальное действие - информационная деятельность, в которой субъект анализирует некоторую ситуацию и формирует свои представления о том, что можно и чего нельзя при возникновении этой ситуации. Полученную структуру будем называть базовой моделью социального действия.

Информационной сущностью социального действия обусловлено его главное свойство: $и$ предмет, и результат социального действия - это инфрормация. Она может как соответствовать объективной реальности, так и не иметь с ней ничего общего. Социальное действие - это не сама реальность, а ее субъективный образ.

Наиболее распространенным социальным действием индивида является социализация ребенка. В результате обретения личного опыта и объяснений (а иногда и наказаний) взрослых в его сознании формируются образы правильного поведения в тех или иных жизненных ситуациях, представления о том, что можно и чего нельзя, и о последствиях нарушения запретов. Именно это является, на наш взгляд, социальным действием маленького человека. Данная деятельность не имеет видимого проявления, тогда как сформировавшиеся модели поведения факторы свободы и необходимости - проявляют себя в виде представлений. Таким образом, социальное действие и его результаты - это субъективная реальность. Вне субъекта (индивида, группы, социального института) и без него социального действия не существует.

Завершая рассмотрение конструктивного подхода к определению сущности и структуры социального действия, обратимся еще раз к идее метода идентификации. Используя подход Э. Дюркгейма, мы предположили, что «социальные факты» можно сравнивать и таким образом определять, благодаря чему действие становится «социальным». Исходя из этого предположения сфрормулирован метод, который по разной реакции социального института на одно и то же действие субъекта позволяет обнаружить изменение в этом действии «социальности».

Результаты применения метода к анализу конкретной ситуации показали, что «социальность» присуща не действию, на которое реагирует «социальный институт», а самому субъекту социальному институту. Этот подход позволил установить присущий только социальному действию результат, определить элементы деятельности по получению данного результата и главное свойство, вытекающее из информационной сущности социального действия.

\section{Ссылки и примечания:}

1. Наумова Е.В. Анализ моделей социальности в современной социологии // Управление человеческими ресурсами: теория, практика, перспективы : сб. науч. ст. / под ред. д-ра экон. наук С.И. Сотниковой. Новосибирск, 2016. Вып. 2. С. 5-19.

2. Там же

3. Девятко И.Ф. Социологические теории деятельности и практической рациональности. М., 2003. 336 с.

4. «Так как социальные явления, очевидно, ускользают от власти исследователя, то сравнительный метод - единственный пригодный для социологии». Дюркгейм Э. Социология. Ее предмет, метод, предназначение. 3-е изд., доп. и испр. / пер. с фрр., сост., вступ. ст. и прим. А. Гофман. М., 2008. С. 176-177.

5. «Социальный факт узнается лишь по той внешней принудительности власти... или по сопротивлению, оказываемому этим фрактом каждой попытке индивида разойтись с ним». Дюркгейм Э. Указ. соч. С. 76.

6. Мы используем термин «представление» как элементарное понятие, которое вербально не определяется. Содержательно под представлением понимается оценка субъектом последствий участия (как собственного, так и других субъектов) в некотором событии в любом качестве (исполнителя действия, объекта воздействия, наблюдателя и т. п.).

7. Субъект социального действия формирует свои представления о том, что в сложившейся ситуации можно каждому ее участнику.

8. Необходимость в форме «должен» легко трансформируется к виду «не может» (не может не сделать, не может отказаться, не может уклониться и т. п.).

9. Действующий субъект сразу или спустя некоторое время рефлексирует и свое действие, и его результат. При этом он либо воспроизводит собственные представления о выполняемой деятельности (факторы свободы и необходимости), либо пересматривает их. Таким образом, социальное действие субъекта сопутствует его предметному действию.

10. Материальный результат деятельности достигается изменением формы, свойств и положения в пространстве исходного материального предмета деятельности. Информационный результат - изменением формы и содержания исходной информации. 


\section{References:}

Devyatko, IF 2003, Sociological theories of activity and practical rationality, Moscow, 336 p., (in Russian).

Durkheim, E \& Gofman, A (comp.) 2008, Sociology. Its subject, method, purpose, 3rd ed., Moscow, pp. 176-177, (in Russian).

Naumova, EV \& Sotnikova, SI (ed.) 2016, 'Analysis of sociality models in modern sociology', Upravleniye chelovecheskimi resursami: teoriya, praktika, perspektivy : sb. nauch. st., Novosibirsk, Issue 2, pp. 5-19, (in Russian). 